\title{
LA NEGOCIACIÓN Y LA CULTURA, ES FUNDAMENTAL CONOCERLA PARA EL ÉXITO EN EL MERCADO.
}

\author{
Elena del Carmen Restrepo Álvarez'
}

Recibido: 21 de mayo de 2013

Aceptado: 12 de agosto de 2013

\section{Resumen}

El término negociación se encuentra en muchas de nuestras actividades, negociación de la paz con la Farc; Colombia y Panamá negociación de un nuevo tratado de libre comercio, negociación entre cafeteros y gobierno. La Negociación entendida, como la búsqueda del restablecimiento de equilibrios y en ningún caso como la exigencia arbitraria de un criterio por sobre otro.

En toda negociación es importante conocer la cultura de nuestro interlocutor, para ser sensible a los matices y diferencias de las personas de un país y de otro, es fundamental para el éxito en el mercado.

Palabras clave: negociación, cultura, mercado .

\section{THE NEGOTIATION AND THE CULTURE, IT IS ESSENTIAL TO KNOW FOR SUCCESS IN THE MARKET.}

\section{Abstract}

The term negotiation is found in many of our activities, negotiation of the peace with the FARC, Colombia and Panama negotiation of a new free trade agreement, negotiation between coffee growers and government. The negotiation understood, as the search for the reestablishment of balances and in any case as the arbitrary imposition of a criterion on another.

In any negotiation is important to know the culture of our partner, to be sensitive to the nuances and differences of the people of a country and of another, it is essential for success in the market.

Keywords: Negotiation, culture, market

${ }^{1}$ Economista agrícola, Especialista en Administración de Empresas, Especialista en Pedagogía para el Aprendizaje Autónomo, Magister en Educación. Docente Escuela de Ciencias Administrativas, Contables, Económicas y de Negocios -ECACEN, UNAD. Elena.restrepo@unad.edu.co 


\section{Introducción}

Recientemente se ha desarrollado abundante investigación sobre la negociación de un modo más formal. Esto se debe prioritariamente a que la negociación es una competencia fundamental en las sociedades modernas en general y de una manera particular en la administración.

Es importante conocer aspectos culturales de los países con los que vamos a negociar, por la trascendencia que tiene para lograr el éxito al entender los comportamientos y hábitos, como la escala de valores que definen estilos de actuar.

Contuci, (2005), afirma: Los actuales sistemas de comunicaciones y transporte han producido un fenómeno fundamental en el comercio internacional que hace que hoy se esté negociando con personas que hasta hace pocos años nos hubiera parecido imposible. Este fenómeno de comunicación globalizada no es solamente una cuestión de idioma, sino que existen otra serie de aspectos que hacen a la efectiva intercomunicación y a la gestación de una interrelación más adaptada a los valores culturales que pueden estar afectando las emociones, el razonamiento y el deseo de acercamiento.

\section{La negociación}

La negociación forma parte del ser humano y de su comportamiento diario y universal.

Siempre en todas nuestras acciones estamos negociando. Puchol (2009: 8), dice: desde niños todos los seres humanos negociamos. Desde bebés aprendemos que, a cambio de nuestras sonrisas, nuestros padres nos proporcionan alimento, limpieza, descanso y amor. Por eso resulta paradójico que, alcanzada la edad adulta, olvidemos aquellas habilidades tan precozmente aprendidas.

Los niños tienen álbumes que coleccionan y necesitan sus cromos el cual van pegando y cuan- do hay compañeros del colegio que coleccionan el mismo álbum empiezan hacer intercambios de los cromos o figuras, para completar más pronto su colección. Cuando sobran después de completar su colección estos cromos son vendidos a otros que no han completado el álbum, observamos como el instinto negociador se instala y se desarrolla desde la infancia, y no nos abandona nunca.

Para Puchol (2009: 4), asevera: el hecho de que solo los humanos negocien reviste a esta actividad, la negociación, de una categoría de proceso superior y muy evolucionado. Su alternativa, no siempre ausente en las relaciones humanas, es que la parte más fuerte, en sentido físico, militar o económico, se apodere y llanamente del bien de la otra parte. Negociar sustituye y supera el enfrentamiento físico o bélico.

Buscando el significado de negociación en el diccionario de la Real Academia de la Lengua Española, encuentro: «Acción y efecto de negociar»; el significado de negociar: "Comerciar, mercar/Tratar por la vía diplomática de nación a nación, un pacto, alianza».

Vemos que la negociación es una acción que se realiza mediante la comunicación de personas para comerciar bien sea un producto o servicio (materias primas, productos terminados, maquinaria, insumos, servicios de logística, etc.), de pendiendo de las necesidades de cada uno. Esto lleva a un efecto que debe producir un resultado que es la satisfacción de esa necesidad, mediante un pacto o una alianza de cumplimiento en un tiempo y lugar.

Para Jackman (2006: 8), afirma: La negociación como un proceso mediante el cual dos o más partes se mueven desde sus posiciones divergentes iniciales hacia un punto donde logran llegar a un acuerdo. 
Otra Puchol (2009: 5), precisa Una negociación es una actividad en la que dos partes, cuyos intereses son en parte complementarios y en parte opuestos, tratan de alcanzar un acuerdo que satisfaga al máximo los intereses de uno y otro, al tiempo que facilita la realización de nuevas negociaciones en el futuro.

Oligastri (2007) señala que: negociar es lo que ocurre en una situación en que las dos partes tienen intereses en conflicto, pero también una zona de conveniencia mutua donde la diferencia puede resolverse.

Vinyamata (2003) sostiene que: la negociación es un proceso interactivo, que se traslapa en situaciones de interdependencia que incluye conflicto de intereses y posibilidades de cooperación con el propósito de alcanzar mediante un acuerdo entre las partes que las partes valoren más que sus respectivas alternativas individuales. Otra definición de negociación, sugiere que: es un proceso a través del cual dos o más partes (personas, ejecutivos, organizaciones, consultores), por sí mismas o por intermedio de otros, procuran llegar a acuerdos.

Tobón (2013: 25) dice: la gran aproximación a la negociación, el buen negociador debe reconocer que a) la negociación se hace con personas con quienes tenemos una relación de interdependencia; b) la negociación es realmente un proceso en el cual se trata de influir en el otro; c) queremos que el otro tome una decisión específica que nos conviene; d) debemos analizar las situaciones que ayudan a que el otro tome tal decisión, así como las que la obstaculizan; e) debemos tener en mente la ganancia mutua y el largo plazo.

Diez (2000) explica: la negociación como un proceso de comunicación entre personas que tienen que tomar una decisión respecto a un tema o cuestión que los involucra.

\author{
«Con la negociación pasa lo \\ mismo que con el baile, \\ Todos tienen que seguir el \\ compás procurando no \\ pisar a la pareja».
}

Anónimo

McClelland (2000) afirma: Los negociadores tienen distintos tipos de motivación, entre ellas tenemos la motivación de ganar, la motivación de agradar, y la motivación del logro del objetivo.

Estas tres motivaciones tienen que ver con el estilo negociador:

1. Motivación de victoria: Los oponentes en la negociación son enemigos a los que hay que batir. Estos negociadores anteponen en general los objetivos del trabajo al de la familia, el ocio, e incluso al dinero. Son grandes trabajadores... y firmes candidatos al infarto del miocardio.

2. Las personas motivadas por el deseo de agradar y complacer, suelen tender a hacer una negociación blanda. En la vida prefieren ser considerados y gozar del aprecio ajeno a obtener victorias. Su negociación tiende a hacer concesiones excesivas, con tal de no estropear las buenas relaciones. En las negociaciones buscan hacer amistades y quedar bien con los oponentes; son serviciales, se preocupan de la comodidad, evitan las discusiones y están inclinados a ceder antes que a luchar.

3. La tercera motivación es la correcta (motivación del logro del objetivo) con el mantener en la medida de lo posible unas buenas relaciones.

Estas personas en las negociaciones hablan y escuchan, invitan a los demás a exponer sus 
opiniones, dan y reciben información, pregunta, controlan el tiempo, intentan sistemas de trabajo que potencien la cooperación.

En estos aspectos se pretende mostrar cómo la personalidad y las motivaciones profundas condicionan hasta cierto punto el estilo negociador.

«Mientras se gana algo, no se pierde nada»

Miguel de Cervantes.

Antes de iniciar cualquier negociación se debe tener en cuenta:

1. Precisar los objetivos de la negociación.

2. El objetivo u objetivos deben ser elevados, pero alcanzables.

3. Los objetivos que no están escritos no existen.

En las relaciones internacionales se considera a la negociación como uno de los tres procedimientos de solución pacífica de conflictos.

Es inevitable que los intereses particulares de una persona, una empresa, una asociación, un partido político, un gobierno, una nación, entren en colisión con los intereses de otras personas, empresas, asociaciones, etc.

La negociación supone la superación o el intento de renunciar al recurso de la fuerza para conseguir nuestros objetivos, buscando un compromiso o un acuerdo que satisfaga en parte las aspiraciones de las dos o más partes enfrentadas y que permita en el futuro la convivencia pacífica de las mismas al tiempo que se asegure la posibilidad de futuras colaboraciones en temas de interés común.

En último término, el objetivo de toda negociación es alcanzar acuerdos inteligentes. Cualquier método de negociación se debe juzgar a la luz de tres criterios:

- Debe producir un acuerdo sensato, si tal acuerdo es posible.

- Debe ser eficiente y

- debe mejorar, o al menos no perjudicar las relaciones entre las partes.

El objeto de una negociación es llegar a un acuerdo sabio y prudente afirma Valls (2008), entre dos partes, para aproximar intereses legítimos, resolver conflictos con justicia, llegar a pactos duraderos, y todo ello, considerando y respetando los intereses del entorno y los conciudadanos.

Negociar, para Jackman (2004: 26) implica: que ambas parten obtengan poder, pero si la negociación es para lograr resultados gana-gana, también incluye renunciar al poder, puesto que ninguna de las partes ganará todo.

Puchol (2009: 49): «La negociación es como una comida en la que hay un plato principal, precedido de unos entremeses y seguido de un postre. Estas fases las denominaremos: antes, durante y después de la negociación».

Valls (2008: 36), afirma que «el poder de negociación puede generarlo la gestión inteligente de los diversos elementos que intervienen en ella». El famoso negociador Herb Cohen (1980) distingue tres variables claves: Información, Tiempo y Poder.

Antes de la negociación o periodo de preparación, de igual forma que no se pude construir sin cimentar antes la obra, no se puede negociar sin hacer una buena preparación.

Para una buena negociación debemos tener información. Si hemos negociado anteriormente con esas personas o empresas, es útil hacer una recopilación histórica, que comprende los siguientes puntos: 


\section{Acerca de nuestros oponentes:}

Resultados anteriores.

Objetivos anteriores.

Estrategias y tácticas que emplearon.

¿Cumplieron los acuerdos?

Personas que intervinieron las otras veces. ¿Serán las mismas esta vez?

¿Qué estilo de negociación adoptaron?

¿Qué roles asumieron las distintas personas del otro equipo?

¿Tienen actualmente problemas financieros?

¿Tienen algún tipo de problemas internos (su-

cesiones, obsolescencia de sus instalaciones) o externos (competidor poderoso, mercado difícil, problemas de impuestos o ambientales? ¿Respecto al negociador principal: sabe negociar? ¿Cuál es su estilo de negociación?

¿Tiene premura de tiempo?

¿En qué medida nos necesitan a nosotros?

Acerca de la negociación propiamente dicha.

Temas importante para unos y otros.

Temas secundarios para uno y otro.

Necesidades que tenemos que resolver.

Proveedores.

Consecuencias económicas y sociales de cerrar / no cerrar el trato para uno y otro.

Consecuencias con el entorno y medio ambientales de cerrar / no cerrar el trato para uno y otro.

\section{Acerca del margen de maniobra.}

Autoridad delegada con que se cuenta para llevar la negociación y cerrar el trato.

A quién, cuándo, cómo y con qué frecuencia debo tener informado.

\section{Acerca de la propia oferta.}

Si se trata de una venta (qué estamos ofreciendo, qué modelo, qué prestaciones, plazo de entrega, garantía, servicio técnico, precio, descuentos o bonificaciones).

Competidores dentro del mercado, los productos que ofrecen, precios, ventajas e inconvenientes competitivos de estas marcas o empresas concurrentes.

\section{Acerca de los objetivos.}

Objetivos máximos, mínimos, medios, Alternativas adicionales.

\section{Acerca del equipo de negociación.}

¿Quiénes van a participar en las sesiones de negociación?

¿Qué rol va desempeñar cada uno y cuántos son?

Si se trata de la venta de maquinaria o tecnología, requeriremos de la asistencia de un ingeniero o de un responsable de producción para que hable técnicamente con la contra parte.

El negociador será una persona amable o una persona que nos pondrá tensos al momento de negociar.

¿Quién va a llevar la conversación?

\section{Acerca del equilibrio de fuerzas}

Puntos fuertes y débiles de nosotros.

Puntos fuertes y débiles de ellos.

En toda negociación debe existir un punto de equilibrio en el que ganemos lo que podamos, pero sin hacer presiones excesivas ni humillar a la otra parte. En una negociación futura, el triunfo de hoy nos puede costar caro.

Las zonas en que se mueve toda negociación son las siguientes:

- Utopía: es la zona de objetivos conscientes de que es muy difícil de alcanzar.

- Ideal: es un acuerdo muy ventajoso para nosotros. En esta zona y en la anterior es donde suelen moverse los negociadores muy competitivos.

- Equilibrio: algunos denominan a esta zona la de los negociadores inteligentes, ya que no aprovecharse de la otra parte, aunque se pueda, permite tener negociaciones futuras.

- Mínimo: es una zona de poco beneficio, en el que nos resignamos a obtener algo, porque en caso contrario provocaríamos la ruptura del trato. Algunos llaman a esta situación salvar los muebles.

- Ruptura o reserva: es el punto en que nos levantamos de la mesa. 
- El proceso durante la negociación encierra los siguientes aspectos:

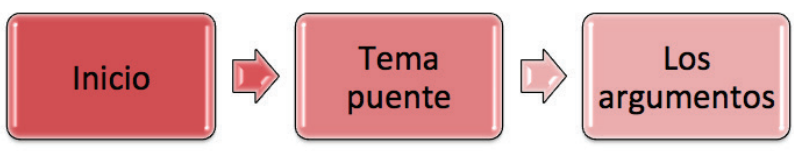

Figura 1. Proceso de negociación

El inicio: la primera recomendación es ser puntual. Con ello manifestamos nuestro respeto por los oponentes.

- Los líderes del equipo negociador harán una presentación muy breve de los participantes (nombre y apellido, cargo que ocupa en la organización).

- Es importante memorizar los nombres, si en caso de dirigirnos a las personas dentro de la negociación, nos dirigimos a ellos empleando la música más agradable a los oídos de cada cual: su propio nombre.

El tema puente: es algo que sea lo suficientemente importante y que produzca el efecto euforizante de esto va por buen camino.

Los argumentos: en negociación argumentamos para mostrar la bondad de nuestra propuesta, o bien para refutar los inconvenientes que la otra parte puede oponer a nuestra propuesta o producto.

La elaboración del argumentario de un producto material, por ejemplo un automóvil, se realiza listando y describiendo las cualidades del producto en cuestión y los servicios que puede prestar. Ejemplo: bajo consumo de gasolina, la velocidad, etc.

Los argumentos constan de varias partes: declaración, datos, garantías, apoyo y reserva.

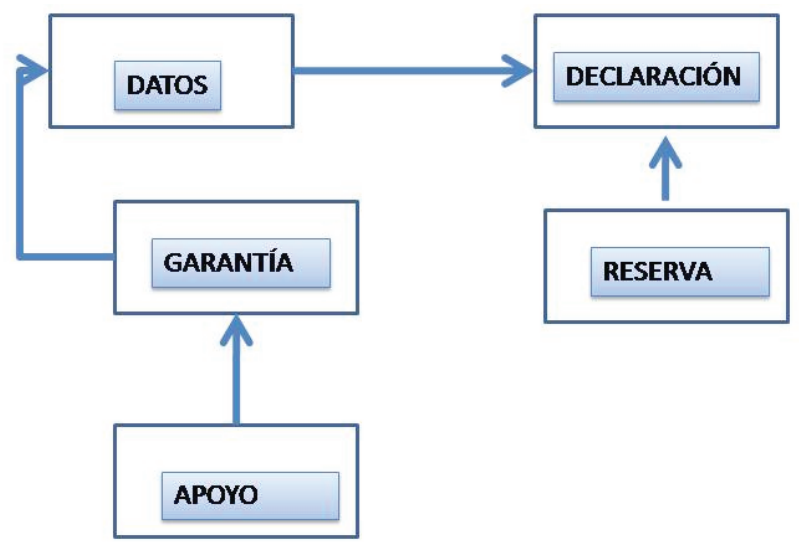

Figura 2. Argumentos del producto

Después de la negociación, la recapitulación: es una exigencia de toda negociación. En medio de tanta discusión es importante hacer con frecuencia recapitulaciones o sumarios de lo ya tratado o acordado, así como de los puntos todavía en discusión.

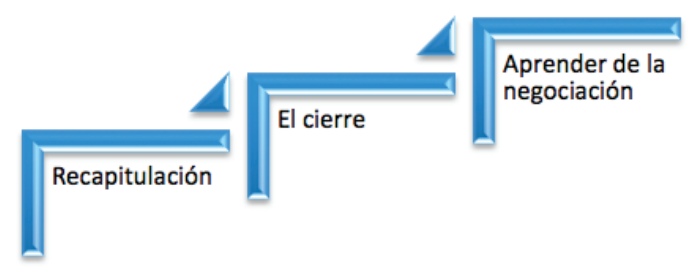

Figura 3. Aspectos a tener en cuenta después de la negociación 
La recapitulación en las fases finales de la negociación es más necesaria, porque de ella se van a extraer los acuerdos y los compromisos que las partes deben asumir.

Otros momentos en que debemos hacer la recapitulación son los siguientes:

- Cuando la negociación se atasca, como un medio para salir del atolladero.

- Cuando queremos persuadirnos y persuadir a la otra parte de qué es lo que realmente cada uno cree que se ha acordado.

- Como prólogo al cierre de la negociación.

El cierre: una negociación puede terminar de dos modos, con acuerdo o sin él.

Aprender de la negociación: si hay acuerdo o no se puede aprender de la negociación, para aplicar en futuras negociaciones.

Para Jackman (2004: 18), dice que: «es importante reconocer que la negociación es un proceso con un punto de partida y un punto final. En una negociación, las partes que intervienen deben estar conscientes de cuándo inicia el proceso y cuándo se termina».

\section{La cultura}

Para Solomon \& Schell (2010: 46), la cultura es una fuerza poderosa que moldea los pensamientos y las percepciones. En su centro existe una geografía nacional, su clima y su mitología; elementos que han dado forma a su historia y opciones religiosas. Sobre estas bases existe una red compleja de valores y creencias, de múltiples capas e intersecciones, entretejidas posiblemente con cuestiones de etnia y clase y moldeadas por la personalidad.

Todo lo anterior incide en el comportamiento de las personas, como percibe y juzga los acontecimientos, la forma en que responde a ellos y los interpreta, y la forma en que usted se comunica en un lenguaje hablado y tácito.
La cultura, difiere en cada sociedad. Las diferencias pueden ser profundas o sutiles, evidentes o invisibles. Siempre presente, pero constantemente cambiante, la cultura penetra el mundo y moldea la forma en que las personas construyen la realidad.

Solomon \& Schell (2010: 47) dice: los negocios no se pueden separar de las personas y de su entorno cultural. Comprender la cultura, es decir, ser sensible a los matices y diferencias de las personas de un país y de otro, es fundamental para el éxito en el mercado. Comprender la cultura afecta principalmente la forma en que usted maneja su negocio, y se traduce directamente en resultados netos.

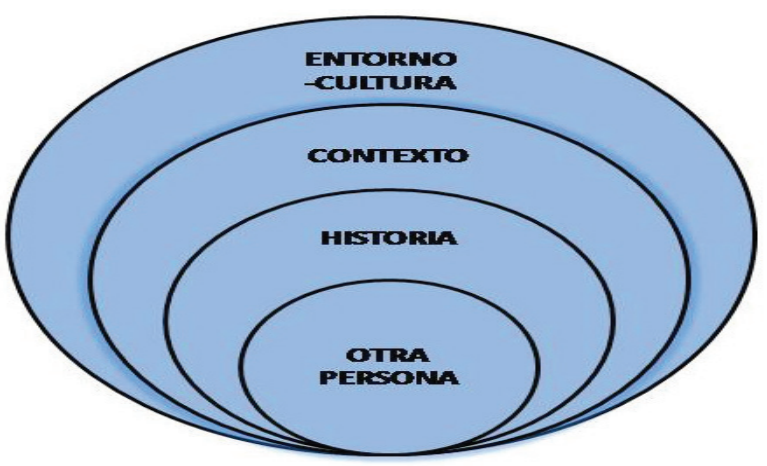

Figura 4. Dimensiones de la cultura

Las dimensiones de la cultura son dos:

\section{Cultura visible:}

1. Incluye el vestido, alimento y costumbres.

2. Su arquitectura, lo que las personas dicen y hacen; cómo se vistes, cómo hablan y sus conductas.

\section{Cultura oculta o invisible:}

1. Incluye los valores, creencias y filosofía que definen la cultura.

2. Como las actitudes hacia el tiempo, comunicación, religión y nociones sobre el bien y el mal. 


\section{Contexto: comprender el panorama}

¿Qué está sucediendo en la organización o en su país de origen, que pueda afectar su negociación?

¿Qué otras cosas están sucediendo en la organización o en su contexto próximo, que nos afecten, internas o externas?

¿Hay otras iniciativas o negociaciones que puedan ayudar u obstaculizar su caso?

¿Está usted en una situación gana-gana o gana-pierde o elementos de ambos?

¿Cómo utiliza esta información a su favor? ¿Qué obstáculos tiene que vencer o retirar para aumentar su posibilidad de éxito?

\section{Historia: evitar problemas}

\author{
¿Qué tipo de organización es? \\ ¿Cuál es el tiempo que tiene en el mercado? \\ ¿Con quiénes negocia normalmente y qué tipo \\ de productos o servicios? \\ ¿Por qué está interesada en negociar con \\ nosotros? \\ ¿Es una nueva negociación o habían estado \\ interesados antes?
}

\section{Otra persona: conocer a su oponente}

¿Quiénes son?

¿Alguien más los conoce y estaría en disposición de suministrar información?

¿Tienen aliados o rivales en común?

¿Qué cosas tienen en común?

¿Cuáles son sus fortalezas o debilidades?

En el lenguaje de la negociación se tienen en cuenta tres áreas principales de comunicación:

- Las palabras que escogemos

- El tono de voz con el que nos expresamos

- Nuestro lenguaje corporal, incluyendo nuestra apariencia

Las palabras que escogemos, según estadísticas en la comunicación cara a cara más del $50 \%$ de nuestro mensaje es manifestado por medio de nuestro lenguaje corporal, vestuario y apariencia, cerca del $40 \%$ por medio de nuestro tono de voz y sólo el $10 \%$ por medio de las palabras; para tener éxito debemos saber manejar estos tres aspectos.

Estas son algunas frases que se pueden utilizar en cada una de las etapas del proceso de negociación; ellas harán que la otra parte responda de manera favorable.

1. Abrir la negociación: «estoy complacido de tener la oportunidad de....»; «gracias por venir a verme para...»; «Demos juntos una mirada a...»

2. Obtener información: «Podrías decirme algo más acerca de...»; «Me gustaría comprender mejor su preocupación por...»; «Como yo entiendo, usted quiere...».

3. Encontrar un motivo común: «Parece que los dos estamos de acuerdo acerca de...».

4. Resistir: «No creo que esto realmente se ajuste a mí. Lo que debería intentar es...».

5. Sacar tiempo para pensar: «Necesito tiempo para pensar acerca de esta propuesta. ¿Podríamos reunirnos de nuevo el...?

6. Hacer concesiones: «Estoy contento de que haya reconsiderado. Ahora podemos...» «¿Qué tal si nosotros...?

7. Solicitar concesiones: «¿Qué tal si usted...?» «Creo que sería justo si...»

8. Llegar a un acuerdo: "Así que estamos de acuerdo en los siguientes puntos...» «Estoy contento porque encontramos la solución a...»

Nuestro tono de voz es un reflejo de cómo nos sentimos. Si nos sentimos frustrados durante una negociación, nuestro tono de voz refleja esto, causando que nos escuchemos impacientes o agresivos.

Si nos sentimos ansiosos, podemos oírnos un poco inseguros o indecisos.

En estos casos no hay una manera firme de tratar con a otra persona. El tono de voz no debe ser un irritador o para que otros saquen partido de la situación. 
Creernos superiores a la otra persona, esto afecta nuestro tono de voz.

La estrategia que puede ayudar a adoptar un tono de voz apropiado, que comunique sus puntos de manera clara y con seguridad a la otra persona, es aprender a manejar las emociones clave de temor y enfado, que pueden surgir durante la negociación.

Debemos manejar el enojo: tener la capacidad de expresar el enojo o frustración, de manera tranquila y calmada a la otra persona durante una negociación, es una herramienta muy poderosa, que comunica no sólo lo que está pensando sino también cómo se está sintiendo.

Esto puede ser más beneficioso para expresar su buena actitud a la otra persona que comunicar sólo sus pensamientos o, aún peor, ignorar su enojo y permitir que éste se filtre por medio de su tono de voz.

Pasos clave para manejar el enojo: Reconocerlo, controlarlo, decidir qué hacer con él y expresarlo de manera calmada y tranquila.

Lenguaje corporal y nuestra apariencia, para crear una buena impresión hágase las siguientes preguntas antes de celebrar una negociación:

- ¿Es una negociación formal o informal? Esto le puede a ayudar a determinar el estilo de vestuario.

- ¿Cómo irá vestida la otra persona? En general estamos más cómodos cuando estamos con personas como nosotros.

- ¿Cómo debería vestirme para asegurar que me vean como igual y me tomen en serio? Un vestido formal y elegante que no llame la atención es lo más apropiado. El vestido puede ser tan irritante para la otra persona como las palabras y el tono de voz que escoja.
- ¿ ¿Existe algún tabú que deba evitar con respecto al vestido? Si es mujer que está celebrando una negociación, pregúntese si debería ponerse una blusa con un escote pronunciado o una falda corta o pantalones. La mujer tiende a ser juzgada en su apariencia más duramente que los hombres, y cualquier cosa que demerite el profesionalismo de una mujer debe ser evitado.

- ¿Cómo debería ingresar a un recinto? Las primeras impresiones son cruciales. Ingresar a un recinto con su cabeza en alto, una sonrisa en su cara y una postura erguida darán una impresión muy diferente a caminar dentro de una habitación con el ceño fruncido o el celular pegado a su oreja.

- ¿Cómo puedo transmitir una imagen positiva de mí misma a las personas con quienes me estoy reuniendo por primera vez? Durante la negociación se debe tener presente la manera de comunicar una imagen positiva. Utilice un lenguaje corporal «abierto», que demostrará una buena disposición para escuchar a la otra persona. Mantenga contacto visual durante la negociación, incluso cuando intervenga en negociaciones donde participan más de dos partes y la otra persona está hablando con alguien más. Demuestre, por medio de su lenguaje corporal y nivel de atención, que en todo momento está concentrado completamente en la negociación.

- ¿Qué irritadores no verbales obstaculizarían mi efectividad como negociador? Alguno de los irritadores no verbales más comunes son: moverse, suspirar y, en general, dar muestras de impaciencia o falta de atención hacia la otra persona o a los hechos.

No apagar el celular durante las reuniones puede ocasionar interrupción y falta de concentración, puede ser interpretado como falta de respeto. Si necesita mantener el teléfono encendido, si 
espera una llamada importante, por ejemplo, explique la situación y solicite permiso a la otra persona para dejar su teléfono activado.

- ¿Qué otro aspecto debo considerar para manejar mi imagen dentro del proceso de negociación? Revise su actitud después de haber terminado la negociación y evalúe cómo las preguntas le ayudaron a prepararse para el proceso, dando la impresión que usted quería comunicar durante la reunión.

En negociación la preparación personal es crucial. Para Valls (2001: 60), Pedir demasiado de uno mismo sin la preparación adecuada será origen de frustraciones. Con preparación, podemos asumir retos impensables para nosotros. Pero ¿qué es prepararse personalmente para una negociación?

Negociar no es cruzarse unas palabras oralmente o por escrito; es mucho más. Nos guste o no, nuestra presencia personal también habla por nosotros: la expresión de nuestra cara, nuestra mirada, el tono de voz, el vestido, los gestos, los olores que emanamos, etc. Si estamos contentos o irritados, si nos sentimos poderosos o humillados, o si disfrutamos o no de la negociación.

Lewicki \& sus colegas, afirman: En las sociedades que requieren que la confianza se construya antes de emprender una relación de negocios, estos expertos sugieren que es necesario demostrar habilidad e integridad. En consecuencia, quizá necesite pasar más tiempo en actividades que por lo general no se consideran valiosas. Aunque quizá piense que hablar de cuestiones personales antes de una reunión o pasar tiempo fuera del trabajo socializando con colegas es una gentileza o simplemente una pérdida de tiempo, piénselo de nuevo. En realidad son las piedras angulares de la confianza, oportunidades para que demuestre sus talentos y elevar su credibilidad.
Las sociedades con un alto nivel de relaciones comienzan por construir confianza. A medida que se conocen las personas se sienten más cómodas haciendo negocios. Las sociedades transnacionales pueden comenzar con las operaciones de negocios y lentamente ir obteniendo más confianza y volviéndose más íntimas.

Con respecto a lo anterior afirma Solomon \& Schell (2010: 124), No existe una manera uniforme o una fórmula fácil para establecer la confianza. La confianza toma tiempo y necesita construirse en las personas sea cual sea el ritmo que requieran. Los líderes eficaces de negocios globales necesitan comprender la importancia de crear confianza con sus colegas y miembros de equipo y reconocer que su ausencia quebrantaría el funcionamiento eficaz de un grupo.

Para Contuci (2005) Al negociar con japoneses ellos se esmeran en la creación de un ambiente amistoso que favorezca luego la expresión de posiciones. Ellos prefieren ocultar los conflictos aun cuando se reúnan para tratar de resolverlos. Las preguntas directas resultan descorteses y suelen responderlas de manera sutil para no ser chocantes.

Contrariamente un norteamericano prefiere el diálogo directo, referido a lo esencial sin permitir que la discreción excesiva provoque lentitud en el tratamiento de los puntos centrales de la reunión de negocios.

Frecuentemente los factores culturales inciden de manera inconsciente en nuestro comportamiento, rara vez pensamos en nuestra cultura, sin embargo influye decididamente en nuestro pensar y actuar. Solo al enfrentarnos con personas de otras culturas podremos apreciar el fuerte impacto que causa en nosotros el contraste de costumbres muy distantes a las nuestras. Por caso será oportuno conocer si los regalos o comisiones son aceptadas 
como algo normal o se los considera un soborno y por lo tanto inmoral. También vale destacar la proxemia o distancia oportuna de tratar a una persona al conversar con ella a fin de no incomodarla por una excesiva cercanía o incurrir en frialdad a consecuencia de un trato distante.

Merece señalarse también lo que hace al manejo del tiempo y la puntualidad, veremos que alemanes, suizos, japoneses y norteamericanos aprecian especialmente un manejo estricto del tiempo, en tanto que españoles y latinoamericanos rechazan la obsesión por la puntualidad.

Para Contuci (2005), actualmente las cosas no son tan simples, los efectos de la globalización han integrado paulatinamente a los mercados y surge la necesaria adaptación cultural para conocer gustos, hábitos y usos que permita acercarse con más precisión a la satisfacción de la demanda.

Contuci (2005), menciona en otras palabras: la negociación interculturas implica un respeto del otro y una consideración por sus valores y sus costumbres, que por más disparatadas que puedan parecer desde nuestra óptica, pueden tener para nuestros interlocutores, mayor tras- cendencia de lo que suponemos, y por ende si fallamos en estos aspectos podríamos estar dificultando negociaciones por ignorar o despreciar cuestiones que para los otros pueden ser importantísimas.

Los vínculos construidos a través del tiempo tienen mucho peso en tanto aluden a obligaciones recíprocas, y esto se advierte en la forma como las conversaciones de negocios se extienden en comidas y pláticas en el ámbito privado, en las cuales unos y otros muestran interés y despliegan conocimientos particulares que anudan la relación. De esta manera los negociadores desarroIlan un conocimiento social- personal profundo $y$ significativo para asegurarse la confiabilidad del interlocutor y la compatibilidad de sus proyectos.

Contuci, (2005), afirma que la gente (siguiendo a Shoonmaker), se expresa mediante cinco dimensiones culturales: los valores, las creencias, las formas de pensamiento, el idioma y las acciones no verbales.

Paz (2004), nos muestra las siguientes características de los negociadores latinoamericanos y la diferencia de seis culturas internacionales frente a cuatro variables de la negociación.

Tabla No. 1. Los latinoamericanos

- Piensan que negociar es resolver un conflicto que requiere el sacrificio de una de las partes, pero prefieren hacerlo de una manera amistosa e informal.

- No se distinguen por la preparación de las negociaciones, pero son brillantes improvisadores.

- Plantean negociaciones a corto plazo, aunque son muy flexibles en el manejo del tiempo.

- Son muy emocionales y utilizan tácticas de poder en la negociación, pero se arriesgan y confían en la contraparte si sienten afinidad y se desarrolla amistad. 
Tabla No. 2. Otras Culturas

\begin{tabular}{|c|c|c|c|c|}
\hline & $\begin{array}{l}\text { ¿Quiénes } \\
\text { negocian? }\end{array}$ & Argumentación & $\begin{array}{l}\text { Toma de } \\
\text { decisiones }\end{array}$ & $\begin{array}{l}\text { Tipo de } \\
\text { acuerdo }\end{array}$ \\
\hline Japoneses & Subalternos & $\begin{array}{l}\text { Información } \\
\text { detallada }\end{array}$ & $\begin{array}{l}\text { En grupo por } \\
\text { consenso }\end{array}$ & $\begin{array}{l}\text { Acta reunión, } \\
\text { palabra de } \\
\text { caballeros }\end{array}$ \\
\hline Árabes & $\begin{array}{l}\text { Los demás } \\
\text { estatus }\end{array}$ & $\begin{array}{l}\text { Mezclada } \\
\text { y personal }\end{array}$ & $\begin{array}{l}\text { Individual, } \\
\text { consulta }\end{array}$ & Verbal, honor \\
\hline Anglosajones & $\begin{array}{l}\text { Los jefes y los } \\
\text { que más saben }\end{array}$ & Utilitaria & $\begin{array}{l}\text { Individual, } \\
\text { el jefe }\end{array}$ & $\begin{array}{l}\text { Escritos por } \\
\text { abogados }\end{array}$ \\
\hline Chinos & $\begin{array}{l}\text { Habla el jefe, } \\
\text { participa el grupo }\end{array}$ & $\begin{array}{l}\text { Deductiva o } \\
\text { muy concreta }\end{array}$ & $\begin{array}{l}\text { Jefe, grupo } \\
\text { obedece }\end{array}$ & $\begin{array}{l}\text { Escritos, } \\
\text { detalles legales }\end{array}$ \\
\hline Franceses & Sólo el jefe & $\begin{array}{l}\text { Retórica, } \\
\text { discusión }\end{array}$ & $\begin{array}{l}\text { Individual, } \\
\text { centralizada }\end{array}$ & $\begin{array}{l}\text { Escritos } \\
\text { de tallados }\end{array}$ \\
\hline Latinoamericanos & Sólo el jefe & $\begin{array}{l}\text { General, vaga, } \\
\text { personal }\end{array}$ & $\begin{array}{l}\text { Individual, } \\
\text { centralizada }\end{array}$ & $\begin{array}{l}\text { Palabra } \\
\text { y escrito legal }\end{array}$ \\
\hline
\end{tabular}

No existen grandes diferencias entre el proceso de negociación que se da entre países del que realizan dos personas del mismo país, porque las principales diferencias son en lo cultural, las expectativas, valores que no son compartidos por ambas partes. En las negociaciones internacionales existe una mayor complejidad en los procesos e instancias de decisión, un mayor fraccionamiento de los intereses propios y de la contraparte, una mayor incidencia de factores públicos y políticos, una dificultad mayor de encontrar instancias de control, conciliación o arbitrio, un plazo más largo en la solución e implementación de las negociaciones y los acuerdos, asimetrías estructurales y casi permanente entre el poder de los países, una mayor formalidad (acuerdos escritos y legales), y una frecuente ocurrencia de negociaciones multilaterales (Ogliastri, 1993).

La negociación no solo se presenta en lo familiar, empresarial, político o extraterritorial, la negociación en cada una de sus facetas, es el camino hacia la resolución de casi cualquier conflicto, sí cada una de las partes involucradas están dispuestas a encontrar la solución adecuada y que las beneficie conjuntamente.
El administrador de empresas tendrá éxito o fracaso en la solución de un problema específico de su organización o individual, dependerá de la capacidad para definirlo y analizarlo, habilidad para seleccionar entre los recursos de acción que se determinen como variables para afrontar los problemas y alcanzar los objetivos trazados para su solución y de la actitud para ejecutar y controlar oportunamente, la decisión tomada, que siempre será susceptible de ser mejorada.

Para Paz ( 1995), la vida, tanto de las organizaciones como de las personas, se desenvuelve dentro de un complejo sistema de oportunidades, alternativas, las cuales conducen a decisiones y acciones que, de ser acertadas, satisfacen necesidades y proporcionan bienestar.

El administrador de empresas, dentro de la nueva dinámica de la geopolítica, la política y la economía mundial, dentro de la nueva gerencia como suministradora de conocimientos para generar resultados, debe dominar los procesos y técnicas de negociación como herramienta fundamental para la solución de conflictos y para el establecimiento y mantenimiento de relaciones perdurables. 
Poder de negociación del administrador de empresas, se basa en los siguientes aspectos:

«Que nunca lleguemos a negociar por temor, pero que nunca le tengamos temor a negociar» (John F. Kennedy, presidente de los Estados Unidos).

1. Haga ofertas. Ir preparado y no improvisar

2. Haga aliados. Realice prenegociaciones. No permita que otros se unan en contra suya.

3. Ampliar el pastel.

4. Recurrir al sentido de la justicia.

5. Ideas para desenvolverse como un adecuado negociador (Nierenberg, 1994):

- La parte más relevante de toda negociación es que es realizada por personas. Seres accesibles, en la medida en que tengamos conocimiento claro y profundo de cuáles son sus intereses y actitudes más frecuentes en diversas situaciones.

- El conocimiento otorga confianza.

- Cada nueva negociación requiere una nueva consideración.

- La investigación objetiva permite obtener una ventaja de cualquier cambio en la negociación.

- El humor desempeña una función vital en los negociadores.

- La importancia de toda reunión se muestra en los arreglos físicos.

- Comenzar toda negociación con una aproximación beneficiosa, para ambas partes anima automáticamente la creatividad.

- Intente conducirse de modo cooperativo más que de forma defensiva.

- Los mejores acuerdos son los que benefician a las dos partes.

6. Ideas para el comportamiento como negociador (Nierenberg, 1994):

- Muchas de las decisiones personales se toman para proteger o mejorar la autoimagen.

- Cada equivocación es una experiencia para ganar sabiduría con el nuevo uso de nuestra propia conciencia.

- Es importante el arte de escuchar.

- La estrategia de cada una de las partes depende de la de la otra.

- Introducir elementos sobre los cuales la otra parte desea hablar.

- La contraparte no se limitará a estudiar la calidad del producto y sus beneficios, sino que tendrá en cuenta la imagen que proyecte el negociador.

- El vendedor debe saber quién toma las decisiones en la compañía compradora.

- La competencia no es tanto un rival sino una posibilidad de alianza.

- Un buen negociador debe saber ganarse la otra parte, no con planes competitivos, sino con ofertas que despierten interés en la otra persona con la cual se va a negociar.

\section{Conclusiones:}

Negociar es algo innato en el ser humano, que debemos estar cultivando frecuentemente de acuerdo con nuestras actividades. Saber negociar, es buscar el gana-gana entre dos personas, para beneficio mutuo no solo de un momento, sino para siempre. Una verdadera negociación es duradera cuando se desarrolla dentro de la cooperación.

Para negociar debemos tener muy claros los objetivos, deben ser alcanzables y estar escritos dentro del proceso, sino se han definido no existen dentro del mismo. En la negociación las partes involucradas, tratarán de alcanzar un acuerdo que los satisfaga al máximo los intereses de uno y de otro.

Al llegar a una negociación, debimos consultar quién era nuestro oponente. No podemos desconocer su cultura, porque son personas y tienen unas dimensiones culturales visibles e invisibles; forman parte de un contexto, de un país, y de una organización, también conoce su historia como organización, éste conocimiento es una gran oportunidad en la negociación. 
Es importante conocer las etapas que se dan dentro de una negociación, como son: inicio, tema puente, los argumentos, la recopilación, el cierre y aprender de la negociación, nos permitirá un mejor desenvolvimiento del mismo.

Y por último no olvidemos que nosotros como negociadores tenemos un lenguaje dentro de la negociación, como son nuestras palabras con que nos comunicamos, el tono de voz y nuestro lenguaje corporal, es la imagen que proyectamos y que debemos saber manejar.

\section{Referencias}

Acosta y Asociados. s.f. Negociación e_learning. - Documento recuperado mayo 10 de 2013

http://www.acostayasociados.com.ar/espanol/demo/1_ el_entorno_de_la_negociacion.htm

Contuci, J. (2005). Negociación. Revista No. 1.

Fisher R., Ury W. (1991). Obtenga el sí: el arte de negociar sin ceder. México: Editorial Penguin Books.

Goleman, D. (1998). La práctica de la inteligencia emocional. Barcelona:, Kayrós.

Documento recuperado mayo 18 de 2013: http://webs. uvigo.es/pmayobre/master/textos/evangelina garcia/ practica inte emocional.pdf

Jackman, A. (2006). Cómo negociar. La vía rápida para lograr los resultados que desea. (1ª. ed.) Bogotá D.C. Panamericana Editorial.
López, A. (2007). Hacer negocios. Cómo ver oportunidades donde nadie lo hace. (1‥ ed.) Madrid: Espasa Calpe, S.A.

Ogliastri, E. 2001. ¿Cómo negocian los colombianos? Bogotá: Alfaomega.

Ogliastri, E. \& Mora, R. (2007). Negociación. Módulo Unad. Estilos de negociación y diversidad cultural. Bogotá: Universidad de los Andes.

Paz, J. 2004. Revista EIA, 1:81-98, Febrero 2004,

Puchol, L., et al., (2009). El libro de la negociación. (3ª . ed.). Barcelona: Ediciones Díaz de Santos.

RAE. Diccionario de la Real Academia de la Lengua Española. Madrid: RAE.

Ramírez, A. (2008). La negociación desigual. (2ª ed.) Madrid:; EDAF.

Solomon, Ch. \& Schell, M. (2010). Diversidad cultural en los negocios. México: Editorial Mc Graw Hill.

Tobón, J. (2013). Método Harvard de negociación. Cómo negociar con Inteligencia. Documento recuperado mayo 18 de 2013:

http://www.jitconsulting.com.co/libros/Harvard-pdf-2 3.pdf

Torres Coronas, T. 2000. Cómo negociar con éxito. La preparación de la negociación. Documento recuperado mayo 10 de 2013.

http://ciberconta.unizar.es/LECCION/negoci/230.HTM

Valls, A. (2008). Negocie, disfrute y gane. Barcelona: Editorial Amat S.I.

Van, A. (2008): El siglo de los mercados emergentes. Bogotá: Grupo Editorial Norma. 